\title{
A Relação Trabalho e Educação e suas Implicações na Educação de Jovens e Adultos.
}

\author{
La Relación Trabajo y Educación y sus Implicaciones en la Educación de \\ Jóvenes y Adultos.
}

The Work and Education Relation and its Implications in the Education of

Young and Adults.

\author{
Daiane Ferreira Ferreira ${ }^{1}$ \\ Vilmar Alves Pereira ${ }^{2}$
}

\begin{abstract}
Resumo
Este trabalho é um recorte do projeto de dissertação que apresenta um estudo sobre a relação Trabalho Educação na modalidade da Educação de Jovens e Adultos - EJA. Um estudo de caráter qualitativo que está sendo desenvolvido nas Escolas Estaduais de Ensino Médio do Município do Rio Grande com educadores (as) da rede que trabalham com a modalidade da EJA. A pesquisa tem como objetivo compreender relevância da relação Trabalho-Educação na constituição dos Educandos/as da Educação de Jovens e Adultos, e em que medida a EJA problematizadora pode se constituir num instrumento de enfrentamento a lógica do mercado de trabalho na rede Estadual de Educação do Município do Rio Grande/Rs? Essa pergunta de pesquisa surgiu das inquietações de como os educadores (as), educandos (as) compreendem sobre a perspectiva de Trabalho e suas implicações na EJA. Esse estudo dialoga com o horizonte da Educação Popular, com o histórico da legislação a cerca da Educação de Jovens e Adultos, com o viés da pesquisa social qualitativa. Como metodologia na coleta de dados utilizamos o Grupo Focal e para a análise de dados será o Discurso do Sujeito Coletivo.
\end{abstract}

Palavras-Chave: Educação Popular, Educação de Jovens e Adultos, Relação Educação e Trabalho.

\section{Resumen}

Este trabajo es un recorte del proyecto de disertación que presenta un estudio sobre la relación Trabajo Educación en la modalidad de la Educación de Jóvenes y Adultos - EJA. Un estudio de carácter cualitativo que está siendo desarrollado en las Escuelas Estaduales de Enseñanza Media del Municipio del Río Grande con educadores de la red que trabajan con la modalidad de la EJA. La investigación tiene como objetivo comprender relevancia de la relación Trabajo-Educación en la constitución de los Educandos / as de la Educación de Jóvenes y Adultos, y en qué medida la EJA problematizadora puede constituirse en un instrumento de enfrentamiento a la lógica del mercado de trabajo en la red Estadual de Educación del municipio de Rio Grande / Rs? Esta pregunta de investigación surgió de las inquietudes de cómo los educadores, los educandos (as) comprenden sobre la perspectiva de trabajo y sus implicaciones en la EJA. Este estudio dialoga con el horizonte de la Educación Popular, con el histórico de la legislación a cerca de la Educación de Jóvenes y Adultos, con el sesgo de la investigación social cualitativa. Como metodología en la recolección de datos utilizamos el Grupo Focal y para el análisis de datos será el Discurso del Sujeto Colectivo.

Palabras claves: Educación Popular, Educación de Jóvenes y Adultos, Relación Educación y Trabajo

\footnotetext{
1 "Mestranda no Programa de Pós-Graduação em Educação - PPGEdu/FURG; Rio Grande; Rio Grande do Sul; Brasil; daiane.ferreira13@outlook.com “. Trabalho apresentado no III Encontro Humanístico Multidisciplinar e II Congresso Latino-Americano de Estudos Humanísticos Multidisciplinares, Jaguarão /RS, Brasil, 2017.

2 "Doutor em Filosofia da Educação pela Universidade federal do Rio Grande do Sul-UFRGS; Rio Grande; Rio Grande do Sul; Brasil; vilmar1972@gmail.com”.
} 


\begin{abstract}
This work is a cut of the dissertation project that presents a study on the relationship Education Work in the modality of the Education of Young and Adults - EJA. A qualitative study that is being developed in the State Schools of High School of the Municipality of Rio Grande with educators of the network that work with the modality of the EJA. The research aims to understand the relevance of the Work-Education relationship in the constitution of Youth and Adult Education Educators, and to what extent the problematizing EJA can constitute an instrument of confrontation with the logic of the labor market in the State Education Network of the Municipality of Rio Grande / Rs? This research question arose out of concerns about how educators, learners understand about the perspective of work and its implications on EJA. This study dialogues with the horizon of Popular Education, with the history of the legislation about the Education of Youths and Adults, with the bias of qualitative social research. As methodology in the collection of data we use the Focal Group and for data analysis will be the Discourse of the Collective Subject.
\end{abstract}

Keywords: Popular Education, Youth and Adult Education, Education and Work Relations.

\title{
Introdução
}

A Educação de Jovens e Adultos (EJA) é uma modalidade de ensino que sofre diversas mudanças de acordo com o período histórico, tanto no que se refere à prática, desde a organização de tarefas e produção de trabalhos, como também no que se refere ao campo teórico desta modalidade. Escrever sobre a EJA é também dissertar sobre o cenário de disputa, de luta e resistência que ao longo da história fez e faz parte de sua constituição. É um campo onde a diversidade se faz presente, onde diferentes protagonistas lutaram e lutam por uma educação mais igual e justa.

É desafiador para qualquer estudioso da área contar um pouco da história da EJA, tão complexa e imersa num universo tão plural. E nessa diversidade pesquisar sobre a EJA e a relação Trabalho Educação é ainda mais desafiador. Alicerçada na educação popular, nos inspiramos na tentativa de também denunciar as mazelas que o sistema capitalista produz e reproduz no sistema educativo do Brasil que é influenciado diretamente pelo Banco Mundial.

A educação popular, a EJA e os princípios e as concepções que as inspiraram na década de sessenta continuam tão atuais em tempos de exclusão, miséria, desemprego, luta pela terra, pelo teto, pelo trabalho, pela vida. Tão atuais que não perderam a radicalidade, porque a realidade vivida pelos jovens e adultos populares continuam radicalmente excludente. (ARROYO, 2005, p.229).

A caminhada da Educação de Jovens e Adultos está intrinsecamente ligada aos olhares que cada momento histórico e político tiveram com essa modalidade. São legislações que reconhecem o direito à formação para aqueles e aquelas que por diferentes motivos interromperam sua formação básica. No entanto, o que se percebe até os dias de hoje é um preconceito com esta modalidade. A falta de investimento por parte dos governos, a falta de formação para os educadores e educadoras da modalidade são fatores que corroboram para 
um olhar desqualificando esta modalidade tão importante para a formação básica das camadas populares.

\section{Educação de Jovens e Adultos e a sua Caminhada de Acordo com o Tempo Histórico.}

A Educação de Jovens e Adultos em vários momentos de sua história carece de registros, mas podemos pensar na EJA como seu marco inicial na História do Brasil a partir da colonização portuguesa, com a chegada dos catequizadores jesuítas, em 1549. Segundo Haddad e Pierro (2000):

No período colonial os religiosos exerciam sua ação educativa missionária em grande parte com adultos. Além de difundir o evangelho, tais educadores transmitiam normas de comportamento e ensinavam os ofícios necessários ao funcionamento da economia colonial, inicialmente aos indígenas e, posteriormente, aos escravos negros (p.109).

O sistema educacional do Brasil sempre esteve conectado com as transformações que ocorriam e ocorrem no cenário político, social e econômico. Desse modo, com a expulsão dos jesuítas e o fim do período colonial, surge então o período Imperial e é no Brasil Império que surge a primeira constituição brasileira, no ano de 1824. De acordo com Haddad e Pierro (2000), a constituição de 1824 apresentava a garantia de uma "instrução primária e gratuita para todos os cidadãos", no entanto, "a garantia de uma escolarização básica para todos, não passou da intenção legal”.

Passado o período Imperial, surge então no Brasil a Primeira República, em 1891. É na Primeira República que a responsabilidade da Educação Básica passa a ser das províncias e municípios e a União assume o ensino secundário e superior. A falta de recursos financeiros nas províncias fez com que o problema do analfabetismo se mantivesse com índices exorbitantes, demarcando mais uma vez a formação das elites e comprometendo a formação das classes populares. Foi neste período, também, que os adultos analfabetos não tinham o direito ao voto e a discriminação que esteve sempre presente, era oficializada na lei.

A Educação de Jovens e Adultos era vista como um ato de caridade e em nenhum momento houve uma preocupação com uma educação especifica para este público. Os adultos analfabetos eram considerados como crianças e incapazes de pensar por si só. No entanto, no início do século XX, começa a haver uma grande mobilização social de educadores e da sociedade, buscando uma melhor qualidade de ensino e também mais escolas, exigindo que o estado fosse responsável pela Educação Básica. Outro fator que fez com que a preocupação com a educação ganhasse mais importância foram os altos índices de analfabetismo do Brasil, 
comparados com outros países da América Latina. Assim, perdemos muito tempo articulando legislações e não as cumprindo, favorecendo as elites e esquecendo as classes populares.

Nesse contexto, na revolução de 1930, também conhecida como Era Vargas, surge a constituição de 1934, constituição esta que marca outro momento para a Educação de Jovens e Adultos, pois demarca o direito de educação para todos como dever do estado. Foi neste período também que o problema do analfabetismo passou a ser reconhecido como um problema social e essa constituição propõe o Plano Nacional de Educação. Em 1938 é criado o Instituto Nacional de Estudos Pedagógicos - INEP, e foram os estudos e pesquisas produzidos neste instituto que deram origem ao Fundo Nacional do Ensino Primário, e, através desse fundo nacional, se articulou um programa de ensino supletivo para jovens e adultos. De acordo com Haddad e Pierro (2000, p.111), “em 1945 o fundo foi regulamentado, estabelecendo que $25 \%$ dos recursos de cada auxílio deveriam ser aplicados num plano geral de Ensino Supletivo destinado a adolescentes e adultos analfabetos".

É importante registrar que em um contexto mundial os movimentos a favor da Educação de Jovens e Adultos ganham uma dimensão ainda maior em virtude da posição que a UNESCO (Organização das Nações Unidas para a Educação, a Ciência e a Cultura) assume com relação a essa problemática social, denunciando as desigualdades entre os países, principalmente no que se refere à educação.

De acordo com o censo, em 1940, pouco mais da metade da população era analfabeta, considerando a população de 18 anos ou mais. No Nordeste e Norte do país estes índices eram ainda mais alarmantes, chegando a $72 \%$ da população. Diante deste cenário preocupante, principalmente para o campo político, já que os analfabetos não tinham o direito ao voto, começam a surgir programas e/ou planos na tentativa de erradicar o analfabetismo. Ressaltamos que desse período, até os anos de 1950, o Governo Federal lança a primeira campanha de Educação de Adolescentes e Adultos (CEAA), embora se observe que existia um esforço da união em diminuir o índice de analfabetos, também existia um forte interesse dos partidos políticos na construção deste novo cenário. O CEAA, para Fávero (2009), “era basicamente assistencialista e suas ações meramente compensatórias” (2009, p.11).

Em um cenário sempre marcado pela luta de uma educação para todos e todas, resistindo aos mecanismos criados pelos governos no processo de elitização da educação, surgem os movimentos que marcam a história da EJA, que são o Movimento de Educação de Base - MEB; De Pé no Chão Também se Aprende a Ler que acontecia em Natal, no Rio Grande do Norte; a União Nacional dos Estudantes coordenava o Movimento Centro Popular de Cultura - CPC, e o Movimento de Cultura Popular do Recife - MCP, este último, 
coordenado pelo saudoso mestre Paulo Freire, tinha como viés a transformação da realidade a partir da cultura, questionando a postura da escola tradicional, em um movimento que valorizava a cultura regional e que tinha o envolvimento da sociedade civil. O Movimento de Cultura Popular do Recife fez história não só pela sua preocupação com a educação, principalmente para os jovens e adultos analfabetos, mas também pelo seu método de pensar essa educação, valorizando a cultura, considerando o contexto desses sujeitos, em uma educação que fosse também política, cidadã, cultural. De acordo com Barreto:

O MCP do Recife desenvolvia várias atividades, entre as quais a Educação de Jovens e Adultos, [...]. A base do movimento eram os círculos de cultura, grupo de pessoas que se reuniam para discutir temas variados, num exercício permanente de "leitura de mundo", pautada principalmente no significado de "cultura", trazendo a questão do ser humano côo ser histórico, produtor de cultura (2005, p. 45).

É nos anos 50 que começam as discussões e a elaboração da primeira Lei de Diretrizes e Bases da Educação Nacional (LDB), promulgada no dia 20 de dezembro de 1961. Esta lei trouxe não só a esperança como também um campo de referência e ressignificação para a educação de toda nação. A LDB teve vigência até 1971.

Em abril de 1964 a sociedade sofre o golpe militar e, consequentemente, a deposição de João Goulart. A revolução no método de alfabetização no Brasil, que ganhava força e agregava apoiadores e parceiros, acaba sendo substituída por forte repressão, censuras, prisões, etc. Nesse contexto, os movimentos populares foram controlados pelos militares, fazendo com que o movimento revolucionário da Educação Popular fosse abruptamente interrompido, bem como seus dirigentes e coordenadores perseguidos. O estado autoritário com suas fortes repressões, como já mencionado, foi o responsável pela redução e quase extinção dos movimentos de Educação Popular, ainda que, durante o período, alguns se mantiveram de forma clandestina e dispersa.

Em 1967, foi promulgada a lei $5.379^{3}$, de 15 de dezembro, que trata sobre a alfabetização funcional e a educação continuada de adolescentes e adultos que deu origem ao MOBRAL - Movimento Brasileiro de Alfabetização. Em 1970, o Mobral se torna fundação, dispondo de valores financeiros bem altos para alcançar o objetivo de erradicar o analfabetismo em 10 anos. De acordo com Fávero (2009), o Mobral, que "foi reformulado com estrutura de fundação se converteu no maior movimento de alfabetização de jovens e adultos já realizado no país, com penetração em praticamente todos os municípios (2009, p.18).

\footnotetext{
${ }^{3}$ Disponível em: <http://www.planalto.gov.br/ccivil_03/leis/1950-1969/L5379.htm>.
} 
O Mobral foi o único movimento de alfabetização que se manteve no período de Ditadura Militar, tendo sua extinção em 1985, mesmo ano que finda a ditadura.

O Mobral perseguiu de maneira análoga o mesmo objetivo de legitimação do regime e de minimização das tensões sociais, mas como programa nacional e laico. [...] ele não foi montado como contra-ofensiva ideológica para neutralizar os efeitos dos movimentos anteriores a 1964, mas como forma de ampliar junto às camadas populares as bases sociais de legitimidade do regime, no momento em que esta se estreitava junto às classes médias em face do Al-5, não devendo ser descartada a hipótese de que tal movimento tenha sido pensado também como instrumento de obtenção de informações sobre o que se pensava nos municípios do interior do país e na periferia das cidades e de controle sobre a população. Ou seja, como instrumento de segurança interna (PAIVA, 1981 p.98).

Com o movimento de repressão provocado pelo regime militar, os movimentos de alfabetização foram sendo silenciados. Em contra partida, outros movimentos como o estudantil, juntamente com setores da igreja católica e organizações da sociedade civil faziam o enfrentamento e resistiam ao estado de exceção. Torturas, perseguição política e o autoritarismo militar deixaram marcas profundas na sociedade brasileira que até a atualidade ainda provocam danos, principalmente no campo político e na democracia.

Em 1987 o estado brasileiro começa as discussões da constituinte e no ano seguinte, no dia 5 de outubro, foi promulgada a Constituição da República Federativa do Brasil. O processo de redemocratização do estado brasileiro faz com que o Mobral seja extinto. É na constituição de 88, no Capítulo III, Seção I, Artigo 208, que o Estado afirma que a educação é um direito de todos e todas.

Art. 208. O dever do Estado com a educação será efetivado mediante a garantia de: I - ensino fundamental obrigatório e gratuito, assegurada, inclusive sua oferta gratuita para todos os que a ele não tiverem acesso na idade própria (BRASIL, 1988).

Embora na constituição não apareça a EJA e suas especificidades, existe uma demarcação de direito social à educação para qualquer cidadão brasileiro. No entanto, embora passado o período do Regime Militar, isso não significa que a democracia no Brasil caminha a passos largos e que a população compreende a importância de um estado verdadeiramente democrático. Nesse sentindo, os capítulos seguintes da política no país ainda seriam de muitas modificações e inseguranças para a população. Em 1990, após quase trinta anos sem eleições diretas, Fernando Collor de Mello venceu as eleições e deu início ao seu pacote administrativo, enxugando gastos, privatizando estatais, demitindo funcionários e realizando o confisco das contas bancárias de trabalhadores e empresários. Cheio de promessas, o governo 
Collor assegurou a implementação de um Programa Nacional de Alfabetização e Cidadania PNAC, no entanto, este programa não obteve muito sucesso e, em 1992, Collor sofre o impeachment, sendo destituído do cargo de presidente da república, assumindo então o vicepresidente, Itamar Franco.

Eleito para a presidência da república em 1994 e em 1998, Fernando Henrique Cardoso, segundo Haddad e Pierro (2000, p.121), "priorizou a implementação de uma reforma político-institucional da educação pública". Passados alguns anos, mais precisamente em 1996, é aprovada a Lei de Diretrizes e Bases da Educação e é a partir dessa lei que a EJA começa a ser percebida, embora a seção dedicada a EJA seja singela e sem muitas inovações. Dessa forma, avançamos um pouco no que se refere aos índices de analfabetismo do Brasil, mas ainda há muito a ser feito, uma vez que a educação representa a base da formação de qualquer cidadão.

A trajetória da educação sempre foi marcada por um espaço de luta, principalmente contra a mercantilização tão fomentada pelo neoliberalismo. Para combater as mazelas provocadas pelo sistema capitalista à educação, movimentos e organizações mundiais se reúnem na tentativa de fazer oposição a esse sistema. Na busca por uma educação para todos e todas que esteja alinhada aos direitos sociais, surgem diferentes movimentos como, por exemplo, o Fórum Mundial da Educação. Estes espaços demarcam não só a preocupação com a educação infantil, Educação Fundamental, a educação do Ensino Médio, superior e profissionalizante, como também, com o analfabetismo e a Educação de Jovens e Adultos. Embora o direito à educação para qualquer cidadão seja reconhecido desde 1948, pela Declaração Universal dos Direitos Humanos, no seu Artigo 26, sabemos que principalmente em se tratando da EJA a oferta desta modalidade ainda não chega próximo do ideal, e mais, sabemos que não basta ofertar a modalidade, é necessário pensar políticas de permanência e dar suporte para que o sujeito conclua a sua formação.

Contudo, a falta de investimento na educação ao longo do tempo vem reproduzindo um momento de grande preocupação quando se pensa na formação do cidadão. Quando falamos em educação, falamos também na conquista da liberdade, no exercício da cidadania, em pessoas mais felizes, que tenham condições de se apropriarem de seus diretos e deveres, da cultura, da política, do lazer dentre tantas situações fundamentais para a formação do sujeito. A falta de investimento e comprometimento dos governos com a educação corroboram para o crescimento da desigualdade social, um problema histórico em que pouco evoluímos nos últimos anos. Nesse sentido, cabe ressaltar, que a América Latina ainda possuí em torno de 36 milhões de analfabetos. 


\title{
A Relação Trabalho e Educação e o Capitalismo
}

É notório que o mundo vem passando por processos acelerados no que tange a sua transformação, impulsionada pela globalização da economia, da política, da cultura, da sociedade e também do meio ambiente. Neste mundo globalizado, as inovações tecnológicas e das ciências surgem a todo instante e exigem da sociedade um maior conhecimento, produzindo novas estruturas de trabalho e também o que chamamos de desemprego estrutural.

A globalização introduziu novos conceitos em termos de eficiência da organização de produção, do modelo de gestão, de perfis de qualificação dos padrões de inversão, das vantagens competitivas, e outros. Essas novas formas organizacionais são caracterizadas pelo aumento da flexibilidade, com redução de custos e o melhoramento da qualidade da produção e no controle de materiais, que resultam em ganhos significativos de produtividade (RIBEIRO, 2003, p.227).

Todas essas mudanças foram fomentadas também pela Primeira Revolução Industrial que se deu no final do século XVIII, e pela segunda Revolução Industrial que aconteceu no final do século XIX, contribuindo com o esforço de tornar o trabalho humano como uma peça desta grande engrenagem que é o capital. É neste contexto que a educação se entrelaça ao sistema capitalista, não por estar de acordo com esta organização econômica, mas sim por determinação direta que o próprio sistema cria como condição do funcionamento do mercado de trabalho. Tem-se, aqui, uma visão da educação baseada na teoria do capital humano e que começou a ser discutida a partir das pesquisas de Schultz, quando ele decide investigar o quanto a qualificação humana, baseada na educação, refletia no desempenho da economia americana, durante o período pós-guerra. Segundo Shultz:

\begin{abstract}
Ao investigar a relação entre os níveis de renda e graus de escolaridade, constatou que os níveis de renda aumentavam em proporção aritmética para os indivíduos que possuíam escolaridade média em relação aos que só possuíam escolaridade primária e aumentavam em proporção geométrica para os que possuíam escolaridade superior. Esta relação seria a prova empírica do "valor econômico da educação" (apud SAVIANI, 2005, p. 23).
\end{abstract}

Nesse viés produtivista da educação, em 1971, no Brasil, foi aprovada a lei $\mathrm{n}^{\circ} 5.692$ que, de acordo com Saviani (2005, p.23), "buscou transportar para as escolas os mecanismos de objetivação do trabalho vigentes nas fabricas". No âmbito do capital humano, acreditava-se que o desenvolvimento das habilidades humanas estava diretamente ligada ao crescimento econômico da sociedade, e essa visão economicista tem como base o Banco Mundial e os empresários (elite capitalista): “O investimento em 'capital humano' passou a constituir-se na 
chave de ouro para resolver o enigma do subdesenvolvimento e das desigualdades internacionais, regionais e individuais" (FRIGOTTO, 2013, p.37).

No entanto, a expectativa em torno da teoria do capital humano que acreditava em uma igualdade social, no desenvolvimento dos países do terceiro mundo e na garantia de melhores empregos, acaba por não se efetivar. A precarização do trabalho e do emprego, o desenvolvimento econômico marcado por uma relação de força e poder é o que observamos ter acontecido e ganhado ainda mais força neste século.

No final dos anos 80, a influência do toyotismo surge nas reformas educativas num viés neoliberal. O que antes era denominada de capacidade/habilidade humana, agora, com a influência do Toyotismo, chama-se de desenvolvimento de competência, e possui, de acordo com a Kuenzer (2005, p.80), “o objetivo de atender às exigências do processo de valorização do capital". Esta nova forma de organização pós-taylorismo/ fordismo, nos mostra um maior esvaziamento na atividade de trabalho, com o trabalhador lidando com várias máquinas, reduzindo a qualificação, fragmentando o trabalho e aumentando a exploração. Nesse sentido, essa organização de gestão de trabalho intensifica o uso da força de trabalho e aprofunda a divisão entre capital e trabalho.

No que concerne à relação que se estabelece com o sistema econômico vigente e o trabalhador, sabemos que os trabalhadores vendem sua força de trabalho para sobreviver e o produto que ele produz não é de sua posse e sim propriedade do capitalista. Ora, mas o que é força de trabalho?

Por força de trabalho ou capacidade de trabalho entendemos o complexo das capacidades físicas e mentais na corporeidade, na personalidade viva de um homem e que ele põe em movimento sempre que produz valores de uso de qualquer tipo (MARX, 2013, p.242).

Nas palavras de Frigotto (2005, s/p):

A força de trabalho expressa sua centralidade ao se transformar em produtora de valores de troca, com o fim de gerar mais lucro ou mais valor aos capitalistas. $\mathrm{O}$ trabalho, então, de atividade produtora imediata de valores de uso para os trabalhadores, se reduz à mercadoria força de trabalho e tende a se confundir com emprego.

Desse modo, o que a classe trabalhadora possui é apenas a força de trabalho que é utilizada pelos capitalistas como meio de lucro, ou seja, o trabalhador vende sua força de trabalho por um determinado período e, no final desse período, irá receber por este trabalho, no entanto, uma pequena parte deste período de trabalho se transforma em pagamento e/ou 
salário, o restante do tempo de trabalho que resta é o lucro do capitalista, o que Marx chama de mais valia.

Para contrapor esse meio de organização do trabalho e do capital, a educação possui um papel importantíssimo como meio de romper esta divisão entre o capital e o trabalho, como também romper a fragmentação do trabalho e o distanciamento entre o conhecimento científico e o saber prático. A educação é uma das principais ferramentas na transformação do sujeito em ser social, que se reconhece na sociedade e também a classe social a qual pertence. Para Ianni:

\begin{abstract}
a importância da educação, da contribuição decisiva que a "educação formal" desempenha na profissionalização e na cultura, no discernimento do espaço e tempo, do presente e passado, do próximo e remoto. Isto porque a educação formal, compreendendo os três níveis, a despeito das diferenças entre ensino público e privado, leigo e religioso, contribui decisivamente para a formação cultural do indivíduo e da coletividade, compreendendo as contradições de transformação da população em povo, sendo este uma coletividade de cidadãos; todos seres sociais em condições de se inserirem nas mais diversas formas de sociabilidade e nos mais diversos jogos de forças sociais (2005, p. 32).
\end{abstract}

No entanto, é importante ressaltar que a o sistema educacional no mundo todo sofre influência direta do Banco Mundial (Banco Internacional de Reconstrução e Desenvolvimento - BIRD). A reprodução da lógica capitalista também se dará no sistema educacional, deixando de lado os valores e os ideais humanísticos e direcionando a educação para o sistema mercantil. Nas palavras de Ianni:

Tudo o que diz respeito à educação passa a ser considerado uma esfera altamente lucrativa de aplicação do capital; o que passa a influenciar decisivamente os fins e os meios envolvidos; de tal modo que a instituição de ensino, não só privada como também pública passa a ser organizada e administrada segundo a lógica da empresa, corporação ou conglomerado (2005, p. 33)

Nessa perspectiva, existe um grande desafio na sociedade que é enfrentar os autos índices de desemprego que assola também os países ditos de primeiro mundo. É importante ressaltar, nas palavras de Gentili que:

A empregabilidade ganhou espaço e centralidade a partir dos anos de 1990, sendo definida como o eixo fundamental de um conjunto de políticas supostamente destinadas a diminuir os riscos sociais do grande tormento do final do século; o desemprego. (2005, p.52).

Assim, o que observamos é que a classe trabalhadora luta arduamente para manter-se empregada e essa fragilidade e insegurança que se apresentam diariamente aos trabalhadores 
corrobora para que o trabalhador (a) sujeite-se às leis do mercado. Com isso, a precarização e a retirada de direitos dos trabalhadores e trabalhadoras principalmente das camadas mais populares, passa a ser uma realidade cruel também do século XXI. As novas gerações sofrerão ainda mais com a precarização do trabalho, que fomenta o crescimento do trabalho informal.

A educação entra nesse contexto como uma ferramenta importante no enfrentamento das desigualdades produzidas pelo sistema capitalista. Logo, torna-se necessário avançar na construção teorico-prática de uma pedagogia verdadeiramente comprometida com a emancipação humana. Não podemos ser reducionistas quando falamos sobre educação, sendo inadmissível que ela seja vista apenas como um meio de atender às demandas do mercado de trabalho e principalmente da lógica empresarial.

A educação é mais um espaço de disputa hegemônica, tendo sua história repleta de conflitos, principalmente por ser regulada e subordinada às necessidades do capital. Cabe aos educadores comprometidos com a educação mudar essa lógica. Obviamente, só este processo de diálogo não é suficiente para romper com esta hegemonia, no entanto, é um dos primeiros passos na construção de uma educação problematizadora e comprometida com a formação social dos sujeitos. Para isso, conforme Mészáros:

\begin{abstract}
Limitar uma mudança educacional radical às margens corretivas interesseiras do capital significa abandonar de uma só vez, conscientemente ou não, o objetivo de uma transformação social qualitativa. [...] É por isso que é necessário romper com a lógica do capital se quisermos contemplar a criação de uma alternativa educacional significativamente diferente. (2008, p.27).
\end{abstract}

Ainda com relação à educação formal como meio de romper com a lógica autoritária global do capital, Mészáros afirma que:

\footnotetext{
Esperar da sociedade mercantilizada uma sanção ativa - ou mesmo mera tolerância de um mandato que estimule a instituições de educação formal a abraçar plenamente a grande tarefa histórica do nosso tempo, ou seja, a tarefa de romper com a lógica do capital no interesse da sobrevivência humana, seria um milagre monumental. É por isso que, também no âmbito educacional, as soluções "não podem ser formais; elas devem ser essenciais". Em outras palavras, eles devem abarcar a totalidade das práticas educacionais da sociedade estabelecida. (2008, p.45).
}

A educação, o trabalho, o capitalismo e a sociedade civil estão intrinsecamente ligados. A existência do homem está intimamente ligada aos fatores econômicos, pois é ela que condiciona a vida do sujeito para outras dimensões referente à sua própria sobrevivência. Logo, o processo de trabalho, também é um espaço de aprendizagens e conhecimentos, onde 
as relações sociais acontecem, onde o trabalhador(a) vão refletindo, descobrindo, discutindo, ao ponto que vão articulando o que se aprende no trabalho com o saber social. Sob esta reflexão é necessário compreender que não pode existir uma separação entre o homo faber e o homo sapiens.

\begin{abstract}
Não há nenhuma atividade humana da qual se possa excluir qualquer intervenção intelectual - o Homo faber não pode ser separado do Homo sapiens. Além disso, fora do trabalho, todo homem desenvolve alguma atividade intelectual; ele é, em outras palavras, um "filósofo", um artista, um homem com sensibilidade; ele partilha uma concepção de mundo, tem uma linha consciente de conduta moral, e portanto, contribui para manter ou mudar a concepção do mundo, isto é, para estimular novas formas de pensamento. (GRAMSCI, 1957, p.121).
\end{abstract}

Nesse sentido, diante do estreito vínculo entre educação e trabalho, a nossa caminhada não é fazer com que este tema seja inserido nas aulas como uma forma de orientar os estudantes a ingressar no mercado de trabalho, mas sim que este estreito vínculo seja uma alavanca para que possamos conhecer e aprender sobre as diferentes formas de cultura, das produções de valores que nos permitem conhecer melhor este sujeito e também contribuir na sua formação. É preciso pensar na educação de forma articulada, por isso, é preciso aproximar a pedagogia escolar da pedagogia moderna.

O objetivo da pedagogia moderna não tem sido outro senão entender os processos complexos de humanização e ajudar os educandos nessa trajetória. O que diferencia a pedagogia moderna é ser "humanista" ou estar a serviço de um projeto - processo de autoconstrução como humanos e naõa estar a serviço de um projeto pré-definido de fora. Educar nada mais é que humanizar, caminhar para emancipação, a autonomia responsável, a subjetividade moral, ética. Nosso objetivo tem sido as relações entre trabalho - educação - humanização - emancipação. (ARROYO, 2013, p.143-144)

Historicamente, a educação, a escola, o conhecimento foram direcionados ou reservados ao poder das elites, ou seja, segundo Guareschi, “a escola seria, pois, o aparelho ideológico do capital" (2014, p.94). Esse dualismo das classes sociais é realidade no mundo todo e não restrito apenas aos países subdesenvolvidos. Para Ciavatta:

No Brasil, o dualismo das classes dominantes sociais, do acesso aos bens e aos serviços produzidos pelo conjunto da sociedade, se enraíza no tecido social através de séculos de escravismo e de discriminação do trabalho manual. Na educação, apenas na metade do século XX, o analfabetismo se coloca como preocupação das elites intelectuais e a educação do povo se torna objeto de políticas de Estado. Mas sua organicidade social está em reservar a educação geral para as elites dirigentes e destinar a preparação para o trabalho para os órfãos, os desempregados. (2005, s/p). 
$\mathrm{Na}$ tentativa de romper com este dualismo, garantindo a qualidade de ensino e educação para estudantes da classe trabalhadora, ou seja, as classes mais populares, surge a possibilidade de implementar o Ensino Politécnico, com sua história enraizada na educação socialista, que pensa em uma formação integral e que de alguma forma busca romper com a lógica imposta pelo capitalismo no espaço escolar.

\title{
Relação Trabalho e Educação e suas Implicações na EJA
}

Nesse primeiro momento, é importante ressaltar que falar sobre a Educação de Jovens e Adultos é dialogar com a educação de classe. Rummert define a modalidade da EJA da seguinte forma:

\begin{abstract}
A Educação de Jovens e Adultos (EJA), regulamentada como modalidade de ensino, é, sem dúvida, uma educação de classe. Assim, se configura, no Brasil, como oferta de possibilidades de elevação da escolaridade para aqueles aos quais foi negado o direito à educação na fase da vida historicamente considerada adequada. É, mais precisamente, uma educação para as frações da classe trabalhadora cujos papéis a serem desempenhados no cenário produtivo não requerem maiores investimentos do estado [...] (2007, p.38).
\end{abstract}

Na atualidade, observamos que a EJA vem mudando de público, pois antes, nas salas de aula, predominava a presença de estudantes adultos, porém, hoje, houve uma inversão com relação à idade dos estudantes da EJA, e os jovens são os que predominam na sua maioria. Essa mudança pode estar ocorrendo por vários fatores, no entanto, nossa pesquisa não busca diagnosticar que fatores são estes, mas se faz importante ressaltar sobre essa mudança de composição das turmas de EJA.

A globalização transforma o cenário sobre o mercado de trabalho. As exigências por uma maior qualificação batem à porta de todos (as) trabalhadores (as), de modo que estes estejam aptos a desenvolver qualquer habilidade. Neste sentido, para Rummert:

imposição da permanente busca individual por qualificação para segurar o ingresso num mercado de trabalho cada vez mais restritivo e marcado por diferentes condições de precarização revestidas por uma aparência de liberdade que valoriza o empreendedorismo, o auto-emprego [...].(2008, p.190)

A escola é uma instituição que ao longo do tempo foi caminhando e se constituindo para atender as necessidades da produção capitalista, seguindo o padrão dado e orientado pelas políticas neoliberais que tem um olhar voltado para o mercado. Assim, a formação escolar reproduz a lógica capitalista e forma cidadãos para se inserirem em uma cultura competitiva e individualista. É neste contexto que a EJA possui um importante papel, o de 
pensar a educação para estes e com estes sujeitos de forma problematizadora e que assuma seu papel como educação emancipadora. De acordo com Ciavatta e Rummert, "a formação humana exige da escola profundas reformulações para abrigar e potencializar a riqueza e diversidade que para ela convergem quando recebe alunos da classe trabalhadora" (2010, p.466).

Desse modo, a educação de jovens e adultos é vista com um olhar compensatório para aqueles que possuem baixa escolaridade, um exemplo disso é o Programa Nacional de Inclusão de Jovens - ProJovem, lançado em 2005 pelo Governo Federal, que direcionou a formação às exigências do mercado. Para combater essas mazelas deixadas e reproduzidas pelo sistema capitalista é necessário pensar em uma educação que tenha um compromisso ético-político. Assim, para Zitkoski e Hammes:

O caminho que se coloca para a cidadania dos jovens hoje é o diálogo entre as diferentes modalidades de saberes, para que na prática possamos formar cidadãos comprometidos com práticas sociais humanizadoras. A partir desse horizonte , podemos entender que o conhecimento, a ciência e a educação só tem sentido se contribuírem com o Ser Mais da humanidade toda. (2014, p.125, grifo do autor).

Nesse sentido, quando falamos na relação educação e trabalho na modalidade da EJA queremos direcionar para o entendimento de uma formação integrada, ou seja, que o trabalho passe a ser visto também como um princípio educativo.

Quando nos referimos ao trabalho como princípio educativo, significa que buscamos superar a dicotomia trabalho manual/trabalho intelectual, incorporar a dimensão intelectual ao trabalho produtivo e formar jovens e adultos trabalhadores capazes de atuar como dirigentes e cidadãos, não apenas como governados. (GRAMSCI 1981, p.144 apud CIAVATTA, 2005).

Assim a história da educação de jovens e adultos está marcada pela luta permanente dos trabalhadores pelo direito ao conhecimento. O currículo da EJA precisa ser revisto, pois é ele que direciona as práticas educativas. Um currículo fragmentado, distante da realidade desses sujeitos só corrobora para o processo de exclusão social.

\section{Por uma Educação Popular de Jovens e Adultos}

A não valorização da Educação de Jovens e Adultos, a falta de recursos destinados a esta modalidade, bem como a falta de formação para os educadores e educadoras desta área, corrobora para que o cenário de desvalorização se mantenha e continue produzindo em larga escala as desigualdades sociais. Assim, a não valorização da EJA faz com que estes sujeitos 
jovens e adultos sejam penalizados outra vez, primeiro porque não concluíram a sua formação na "idade certa", depois porque quando o sujeito procura um espaço para terminar sua formação através da EJA, muitas vezes, esses espaços negam a diversidade desses sujeitos, colaborando para a não adaptação deste adulto à realidade da escola, negando pela segunda vez a sua formação.

Desse modo, para resolver os problemas sociais de um país é preciso investir massivamente na educação, em todas suas modalidades. Para Gadotti:

\begin{abstract}
Não há sociedades que tenham resolvido seus problemas sociais e econômicos, sem equacionar, devidamente, os problemas de educação, e, não há países que tenham encontrado a solução de seus problemas educacionais, sem equacionar, devida e simultaneamente, a educação de adultos e a alfabetização (2014, p.16).
\end{abstract}

Assim, cada vez mais se faz necessário pensar uma política nacional de educação de jovens e adultos que caminhe junto e dialogue com a Educação Popular. É preciso reconhecer e legitimar o conhecimento que existe nas comunidades e que é compartilhado pelos sujeitos que ali estão, pensando neste saber popular, da cultura, das crenças que um povo traz em si. É esse saber popular juntamente com o saber científico que dará sentido ao processo de formação dos educandos e educandas da EJA.

É preciso pensar uma Política Nacional de Educação de Jovens e Adultos que seja engajada com os estados e municípios, que dialogue e construa de forma conjunta com os movimentos de alfabetização e EJA que tem por todo o país, contando com a parceria de ONG's, sindicatos, núcleos educacionais, a sociedade civil, os movimentos sociais, os educadores e educadoras, pois é preciso ouvir todos e construir com todos, baseados e alicerçados na Educação Popular.

Diante de um modelo oficial de educação compensatória, a educação popular não se propõe originalmente como uma forma "mais avançada" de realizar a mesma coisa. Ela pretende ser uma retotalização de todo o projeto educativo, desde um posto de vista popular (BRANDÃO, 2006, p.82)

Não podemos pensar uma política de ação sem considerar a experiência desses diferentes sujeitos que passam sua vida envolvidos na luta por uma educação de qualidade, justa e igualitária. É preciso unir forças para construir uma política educacional da EJA que seja capaz de superar as inúmeras desigualdades sociais produzidas durante esses 517 anos de Brasil pós-descobrimento. Neste sentido, se faz necessário pensar uma educação que esteja engajada politicamente, que respeite o saberes de mundo de cada sujeito, que tenha 
compromissos éticos e que seja comprometida com a transformação social, que seja uma educação que olhe para as classes populares, pois sãos estes sujeitos que sofrem e que são diariamente excluídos por um sistema hegemônico que se apresenta na forma de educação bancária.

\footnotetext{
A educação popular caracteriza-se, portanto, por sua identidade com as lutas e formas de organização de classes populares em seus desafios concretos de busca de emancipação sócia, pois se volta para a necessidade de os movimentos sociais populares estabelecerem suas práticas pedagógicas e se organizarem com ideias e estratégias de luta contra-hegemônica diante da lógica social excludente. (ZITKOSKI, 2013, p.49).
}

Desse modo, pensar que é possível uma mudança revolucionária na sociedade é acreditar que, em algum momento (e que seja em breve), os governos comecem a respeitar a educação como ela merece. É investir em educação pública e que esta seja de qualidade, pois a educação é um direito de todos e todas e, ainda no século XXI, o Brasil mantém altos índices de analfabetismo, assim como de jovens que abandonam a escola ainda nos anos iniciais da Educação Básica. Se continuarmos caminhando na contramão e fazendo da educação mais um espaço de negócios com os senhores do Capitalismo, estaremos fadados ao fracasso e ampliando os índices de desigualdades sociais.

Não podemos negar que ter escolas públicas democráticas, alinhadas com a Educação Popular, na prática, principalmente na Educação de Jovens e Adultos, seja uma tarefa fácil, mas, ainda assim, é necessária. Precisamos começar a construir essa possibilidade para que tenhamos uma sociedade realmente justa com uma educação progressista e socialista.

Deste modo, pensar na Educação de Jovens e Adultos alicerçada nas concepções da Educação Popular nos dá um horizonte na construção de uma educação humanizadora e que a EJA não seja vista como política compensatória, mas sim uma política de direito.

\section{Considerações Finais}

A Educação tem sua história marcas de luta e resistência, principalmente contra a mercantilização tão fomentada pelo neoliberalismo. São diferentes instituições, movimentos sociais, educadoras e educadores que lutam por uma educação de qualidade, pela valorização deste setor tão importante na formação do cidadão. Embora o direito à educação para qualquer cidadão seja reconhecido desde 1948, pela Declaração Universal dos Direitos Humanos, no seu Artigo 26, sabemos que principalmente em se tratando da EJA a oferta desta modalidade 
ainda não chega próximo do ideal, e mais, sabemos que não basta ofertar a modalidade, é necessário pensar políticas de permanência.

Contudo, quando falamos em educação, falamos também na conquista da liberdade, no exercício da cidadania, em pessoas mais felizes, que tenham condições de se apropriarem de seus diretos e deveres, da cultura, da política, do lazer dentre tantas situações fundamentais para a formação do sujeito. A falta de investimento e comprometimento dos governos com a educação corroboram para o crescimento da desigualdade social, um problema histórico em que pouco evoluímos nos últimos anos.

Precisamos escrever uma história diferente para educação no Brasil, sobretudo para EJA. Vivenciamos hoje, uma onda conservadora que retira os direitos da classe trabalhadora, ao mesmo tempo que garante benefícios exorbitantes para os ruralistas, políticos, Judiciário, enfim, para aqueles que possuem a maior fatia das riquezas deste país. E a educação, vai sendo vendida aos poucos, quando se tira direitos do povo, quando se congela investimentos por 20 anos neste setor e em outros que é fundamental para manter a boa qualidade de vida. Hoje no Brasil, a educação pública esta sendo esquecida, sem investimento, sem respeito, sem perspectivas de futuro. O que teremos logo ali? Uma sociedade sem sonhos, sem esperanças, sem utopias.

\section{Referências}

ARROYO. M. A educação de jovens e adultos em tempos de exclusão. In: Construção coletiva: contribuições à educação de jovens e adultos. Brasília: UNESCO, MEC, RAAAB, 2005.

ARROYO, M. Trabalho - educação e teoria pedagógica. In: FRIGOTTO, Gaudêncio (org.). Educação e crise do trabalho: perspectivas de final de século. $12^{\mathrm{a}}$ ed. - Petrópolis, RJ: Vozes. 2013.

BARRETO, S. N. O processo de alfabetização na MOVA RS: narrativas e significados na vida das mulheres. 2005. Dissertação (Mestrado em Educação) - Programa de Pós-Graduação em Educação, Fundação Universidade do Rio Grande, Rio Grande, 2005.

BRANDÃO, C. R. O que é educação popular. São Paulo: Brasiliense, 2006.

CIAVATTA, M. A FORMAÇÃO INTEGRADA a escola e o trabalho como lugares de memória e de identidade. 2005. Disponível: http://www.uff.br/trabalhonecessario/images/TN_03/TN3_CIAVATTA.pdf Acesso $16 / 10 / 2017$ 

CURRÍCULO NA EDUCAÇÃO DE JOVENS E ADULTOS INTEGRADA À FORMAÇÃO PROFISSIONAL. Educ. Soc., Campinas, v. 31, n. 111, p. 461-480, abr.-jun. 2010

FÁVERO, O. Lições da história: os avanços de 60 anos e a relação com as políticas de negação de direitos que alimentam as condições do analfabetismo no Brasil. In: OLIVEIRA, I.B.; PAIVA J. (org.). Educação de jovens e adultos. Petrópolis, RJ: DP et Alii, 2009.

FRIGOTTO, G. (Org). Educação e Crise do Trabalho. 12ª ed. - Petrópolis,RJ: vozes, 2013.

FRIGOTTO, G. Concepções e mudanças no mundo do trabalho e o ensino médio. In: Gaudêncio Frigotto; Maria Ciavatta; Marise Ramos. (Org.). Ensino Médio Integrado: Concepção e contradição. 1ed.São Paulo: Cortez, 2005.

GADOTTI, M. Por uma Política Nacional de Educação Popular de Jovens e Adultos. $1^{\text {a }}$ ed. São Paulo: Moderna: Fundação Santillana, 2014

GUARESCHI, P. A Sociologia crítica: alternativas de mudança. 64ª ed. Porto Alegre, EDIPUCRS, 2014.

GENTILI, P. Três Teses Sobre a Relação trabalho e Educação em Tempos Neoliberais In: LOMBARDI, José; SAVIANIA, Dermeval; SANFELICE, José. (Org.). Capitalismo, Trabalho e Educação. 3.ed. - Campinas, SP: Autores Associados, 2005.

GRAMSCI, A. Os Intelectuais e a Organização da Cultura. Trad.de Carlos Neto Coutinho. Rio de Janeiro: Civilização Brasileira, 1982.

HADDAD, S; DI PIERRO, M. C. Escolarização de jovens e adultos. Revista Brasileira de Educação, n $14,2000$.

IANNI, O. O Cidadão do Mundo. In: LOMBARDI, José; SAVIANIA, Dermeval; SANFELICE, José. (Org.). Capitalismo, Trabalho e Educação. 3.ed. - Campinas, SP: Autores Associados, 2005.

MARX, K. O Capital: crítica da economia política: Livro I: o processo de produção do capital; [tradução de Rubens Enderle]. São Paulo: Boitempo, 2013.

MÉSZÁROS, I. A Educação Para Além do Capital. 2ª ed. São Paulo: Boitempo, 2008.

PAIVA, J. Mobral: Um Desacerto Autoritário. Revista Síntese. V.8, N.23, p. 83-114, 1981.

RIBEIRO, J. Globalização, Mercado de Trabalho e Educação. Revista de Ciências da Educação, Lorena: Centro Unisal, ano 5, n.8, jun. 2003

RUMMERT, S. A educação de jovens e adultos trabalhadores brasileiros no século XXI: O "novo" que reitera antiga destruição de direitos. Revista de Ciências da Educação, n.2, jan./abr. 2007.

RUMMERT, S. Educação de jovens e adultos trabalhadores no Brasil atual: do simulacro à emancipação. Perspectiva. Florianópolis, v.26, n.1, p.175-208, jan./jun.2008. 
SAVIANI, D. Transformações do Capitalismo, do Mundo do Trabalho e da Educação. In: LOMBARDI, José; SAVIANIA, Dermeval; SANFELICE, José. (Org.). Capitalismo, Trabalho e Educação. 3.ed. - Campinas, SP: Autores Associados, 2005.

ZITKOSKI, J. A Pedagogia das Marchas e a Educação Popular: Lutas e Esperanças no contexto Latino-Americano. In: PEREIRA, Vilmar; DIAS, José Roberto; ALVARENGA, Bruna. (org.). Educação Popular e a pedagogia da contramarcha. Passo Fundo, RS: Méritos. 2013.

ZITKOSKI, J; J. HAMMES, L. Juventude, educação e cidadania: os desafios da participação social e política. REVISTA DEBATES, Porto Alegre, v. 8, n. 2, p. 119-139, mai.-ago. 2014. Disponível: http://seer.ufrgs.br/index.php/debates/article/viewFile/46470/31160 Acesso $16 / 10 / 2017$ 